Table 1. Description of psychiatric symptoms registered in the database for TNF- $\alpha$ inhibitors

\begin{tabular}{lc}
\hline Characteristics & Patients (Total = 71) \\
\hline Major psychiatric symptoms: & $11(15 \%)$ \\
- Manic episode & $8(11 \%)$ \\
- Acute psychosis & $3(4 \%)$ \\
Minor psychiatric symptoms: & $60(85 \%)$ \\
- Anxiety/Nervousness & $10(14 \%) / 6(8 \%)$ \\
- Insomnia or decreased need for sleep & $31(44 \%)$ \\
- Psychomotor agitation/Aggressiveness & $6(8 \%) / 8(11 \%)$ \\
- Hallucinations & $7(10 \%)$ \\
- Libido exacerbation & $2(3 \%)$ \\
- Euphoria, grandiosity & $4(6 \%)$ \\
- Derealization, depersonalization & $3(4 \%)$ \\
Psychiatric side effect improved: & $45(63 \%)$ \\
- TNF- $\alpha$ Inhibitors withdrawn & $32(45 \%)$ \\
- TNF- $\alpha$ Inhibitors not withdrawn & $9(13 \%)$ \\
- Missing data & $4(6 \%)$ \\
Psychiatric side effect did not improved: & $16(22 \%)$ \\
- TNF- $\alpha$ Inhibitors withdrawn & $8(11 \%)$ \\
- TNF- $\alpha$ Inhibitors not withdrawn & $4(6 \%)$ \\
- Missing data & $3(4 \%)$ \\
Missing data improved/not improved & $10(14 \%)$ \\
\hline
\end{tabular}

DOI: 10.1136/annrheumdis-2017-eular.1610

\section{SAT0145 INFLUENCE OF BODY MASS INDEX (BMI) ON THE DISEASE INFLAMMATORY ACTIVITY AND TREATMENT REPONSE IN PATIENTS WITH RHEUMATOID ARTHRITIS}

A. Villalba Yllan ${ }^{1}$, V. Navarro Compan ${ }^{1}$, C. Plasencia Rodriguez ${ }^{1}$, D. Peiteado Lopez $^{1}$, G. Bonilla Hernan ${ }^{1}$, L. Nuño Nuño ${ }^{1}$, A. Martinez Feito ${ }^{2}$,

D. Pascual-Salcedo ${ }^{2}$, C. Diego ${ }^{2}$, A. Balsa Criado ${ }^{1} \cdot{ }^{1}$ Rheumatology;

${ }^{2}$ Immunology, Hospital Universitario la Paz, Madrid, Spain

Background: The use of biological therapy (BT) in rheumatoid arthritis (RA) has supposes a very important change in the disease's treatment and prognosis. Drugs like Anti-TNF $\alpha$ have proven unquestionable effectiveness. However, the lack or loss of such effectiveness over time raises the dilemma of what factors may influence it. There are studies that suggest the influence of BMI on the efficacy of these drugs and therefore on the control of the disease.

Objectives: To determine the influence of BMI on disease activity and response to treatment with infliximab (ifx) in patients with RA.

Methods: A retrospective observational study of a population of 76 patients with RA who received infliximab treatment, in a standard guideline of $3 \mathrm{mg} / \mathrm{kg}$, in our service between 2000 and 2016 inclusive. The BMI was classified for some sub-studies in four categories: low $(<18.5)$, normal $(=18.5-<25)$, overweight $(=25-<30)$ and obesity $(=30)$. Disease activity was determined by DAS28 at three times: at baseline, at 6 months and at the year of infliximab treatment; Response to treatment was assessed by deltaDAS28 and EULAR response at 6 months and 1 year of treatment. The EULAR response was classified into two categories: "yes" (DeltaDAS28 $>1.2$, or $>0.6$ and DAS28 $<5.1$ ) and "no" (DeltaDAS28 <.6, or $<5.1$ ). First, activity and response rates to treatment were compared in these four groups over the three periods. A regression analysis was then performed for BMI and both activity and response to treatment.

Results: Characteristics of the 76 patients included in the study when initiating IFX therapy were: $66(86.8 \%)$ were women, median (range) age $54(21-83)$ years, $77, \% \mathrm{RF}+, 81 \% \mathrm{ACPA}+$, disease duration $10,8(1,0-39,0)$ years, $59 \%$ with concomitant methotrexate and $55 \%$ with other DMARDs. Median (range) BMI was $25,5(16,7-40,2) \mathrm{kg} / \mathrm{m}^{2}$. According to BMI, patients with underweight, normal, overweight and obesity were $0(0,0 \%), 41(53,9 \%), 22(28,9 \%)$ and $13(17,2 \%)$, respectively. The association between BMI and disease activity (median DAS28 (p25-p75)) is shown in Table 1:

Table 1

\begin{tabular}{|c|c|c|c|}
\hline & Normal & Overweight & Obesity \\
\hline DAS28 bas & $5,63(4-84-6,30)$ & $5,44(4,45-6,73)$ & $6,25(4,42-7,07)$ \\
\hline DAS28 6m & $3,90(2,89-5-12)$ & $3,97(3,32-5,43)$ & $4,80(3,35-5,72)$ \\
\hline DAS28 1y & $3,91(2,89-5,01)$ & $3,69(2,97-5,29)$ & $4,48(2,70-5,87)$ \\
\hline
\end{tabular}

The association between BMI and treatment response (median deltaDAS28 (p25-p75) and EULAR response (\%)) is shown in Table 2:

\begin{tabular}{lcccc} 
Table 2 & \multicolumn{5}{c}{ Obesity } & $p$ \\
\hline DDAS28 & Normal & Overweight & & \\
$\Delta$ DAS28 0-6m & $1,72(0,84-2,77)$ & $1,39(0,38-2,49)$ & $0,77(0,40-1,59)$ & 0,2 \\
DAS28 0-1y & $1,56(0,81-2,74)$ & $1,77(, 092-2,92)$ & $1,20(0,73-1,90)$ & 0,2 \\
EULAR response 6m & 70,7 & 68,2 & 30,8 & 0,065 \\
EULAR response 1y & 61,0 & 54,5 & 61,5 & 0,065 \\
\hline
\end{tabular}

In the longitudinal analysis, a trending but not statistically significant relationship between adjusted BMI and DAS28 was observed at six month and at one year of treatment onset: $\beta: 0,051 ; 95 \% \mathrm{Cl}(-0,06$ to 0,109$)$ and $\beta: 0,037 ; 95 \% \mathrm{Cl}(-0,022$ to 0,097 )
Conclusions: BMI seems to influence, in a non significantly manner, in disease activity and in treatment response in RA treated with infliximab. Obesity BMI values are associated with increased activity and a lower response to this treatment than lower BMI values.

Disclosure of Interest: None declared

DOI: 10.1136/annrheumdis-2017-eular.4449

\section{SAT0146 RANDOMISED DOUBLE-BLIND STUDY SHOWS COMPARABLE LONG-TERM EFFICACY AND SAFETY BETWEEN RITUXIMAB BIOSIMILAR CT-P10 AND INNOVATOR RITUXIMAB IN PATIENTS WITH RHEUMATOID ARTHRITIS: 48-WEEK RESULTS}

C.-H. Suh ${ }^{1}$, E. Chalouhi El Khouri ${ }^{2}$, P. Miranda ${ }^{3}$, F. F Cons Molina ${ }^{4}$, P. Shesternya ${ }^{5}$, F. Medina-Rodriguez ${ }^{6}$, P. Wiland ${ }^{7}$, S. Jeka ${ }^{8}$,

J. Chavez-Corrales ${ }^{9}$, T. Linde ${ }^{10}$, P. Hrycaj ${ }^{11}$, I. Hospodarskyy ${ }^{12}$

M. Abello-Banfi ${ }^{13}$, J. Jaworski ${ }^{14}$, M. Piotrowski ${ }^{15}$, W. Park ${ }^{16}$, S.C. Shim ${ }^{17}$

S.J. Lee ${ }^{18}$, S.Y. Lee ${ }^{18}$, D.H. Yoo ${ }^{19} .{ }^{1}$ Ajou University School of Medicine, Suwon, Korea, Republic Of; ${ }^{2}$ Clinica Internacional, Lima, Peru; ${ }^{3}$ Centro de Estudios Reumatológicos, Santiago, Chile; ${ }^{4}$ Centro de Investigacion en Artritis y Osteoporosis, Mexicali, Mexico; ${ }^{5}$ KrasSMU, Krasnoyarsk, Russian Federation; ${ }^{6}$ Biologics Especializados SA, Mexico City, Mexico; ${ }^{7}$ Medical University, Wroclaw; ${ }^{8}$ 2nd University Hospital, CM UMK, Bydgoszcz, Poland; ${ }^{9}$ Clinica San Borja, Lima, Peru; ${ }^{10}$ Rheumatology Medical Center, Halle/Saale, Germany; ${ }^{11}$ Poznañ University of Medical Sciences, Poznañ, Poland; ${ }^{12}$ Ternopil Medical University, Ternopil, Ukraine; ${ }^{13}$ Centro Integral de Reumatologia del Caribe, Barranquilla, Colombia; ${ }^{14}$ Reumatika - Centrum Reumatologii, Warszawa;

${ }^{15}$ Medical University of Lublin, Lublin, Poland; ${ }^{16}$ IN-HA University, School of Medicine, Incheon; ${ }^{17}$ Chungnam National University Hospital, Daejeon;

${ }^{18}$ Celltrion, Inc., Incheon; ${ }^{19}$ Hanyang University Hospital for Rheumatic Diseases, Seoul, Korea, Republic Of

Background: In phase 1 trials (NCT01534884 and NCT01873443), pharmacokinetic equivalence of CT-P10, biosimilar of rituximab, to innovator rituximab (RTX) was demonstrated. In the phase 3 study, equivalence of PK and efficacy up to week 24 were achieved between CT-P10 and RTX (US and EU sourced) $)^{1,2}$.

Objectives: To investigate the long-term efficacy, pharmacodynamics, immunogenicity and safety of CT-P10 up to week 48.

Methods: Patients with rheumatoid arthritis were randomly assigned to CT-P10, US-RTX or EU-RTX, in combination with MTX. The patients received 2 treatment courses at Week 0 and 24, each consisting of 2 infusions of $1000 \mathrm{mg}$ study drug at 2-week interval.

Results: A total of 372 patients were randomised, and 330 patients completed the 2nd course treatment. DAS28 scores through Week 48 were comparable between CT-P10 and US/EU-RTX (Figure), as well as the proportion of ACR responses at Week 48 between the CT-P10 and combined rituximab groups; $81.3 \%$ and $79.8 \%$ for ACR $20,55.4 \%$ and $53.9 \%$ for ACR50, and $31.7 \%$ and $33.7 \%$ for ACR 70 , respectively.

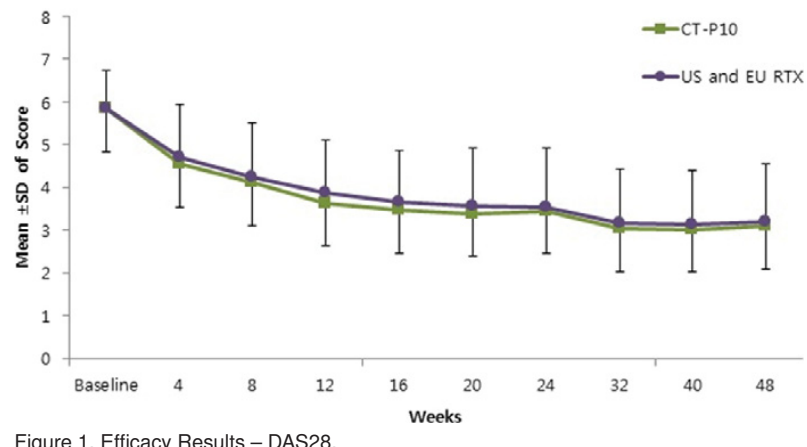

Figure 1. Efficacy Results - DAS28.

B-cell depletion was comparable from after the 1st infusion and up to Week 48. Number (\%) of patients with positive anti-drug antibodies in the CT-P10, US-RTX, and EU-RTX was 7 (4.9), 13 (9.4), and 5 (8.6), respectively at Week 48. The safety profile was also similar across groups (Table).

Table 1. Summary of Safety Profile [n (\%)]

\begin{tabular}{lcccc}
\hline & $\begin{array}{c}\text { CT-P10 } \\
(\mathrm{N}=161)\end{array}$ & $\begin{array}{c}\text { US-RTX } \\
(\mathrm{N}=151)\end{array}$ & $\begin{array}{c}\text { EU-RTX } \\
(\mathrm{N}=60)\end{array}$ & $\begin{array}{c}\text { Reference Products } \\
(\text { US-RTX + EU-RTX) } \\
(\mathrm{N}=211)\end{array}$ \\
\hline $\mathrm{AE}$ & $122(75.8)$ & $96(63.6)$ & $37(61.7)$ & $133(63.0)$ \\
Serious Adverse Event & $13(8.1)$ & $14(9.3)$ & $2(3.3)$ & $16(7.6)$ \\
Infection & $61(37.9)$ & $53(35.1)$ & $17(28.3)$ & $70(33.2)$ \\
Serious infection & $2(1.2)$ & $3(2.0)$ & 0 & $3(1.4)$ \\
Infusion related reaction (IRR) $)^{\star}$ & $33(20.5)$ & $12(7.9)$ & $13(21.7)$ & $25(11.8)$ \\
Malignancy & 0 & $2(1.3)$ & $1(1.7)$ & $3(1.4)$ \\
Progressive multifocal & & & & 0 \\
\multicolumn{1}{l}{ leukoencephalopathy } & 0 & 0 & 0 & \\
\hline
\end{tabular}

${ }^{*}$ None of IRR were serious or led to study drug discontinuation. 
Conclusions: This phase 3 randomised controlled trial demonstrated the comparability of CT-P10 with two rituximab in terms of efficacy, pharmacodynamics, immunogenicity and safety for 1 year.

\section{References:}

[1] Suh $\mathrm{CH}$, et al. 2016 ACR Abstract No. 1634.

[2] Yoo DH, et al. 2016 ACR Abstract No. 1635

Disclosure of Interest: C.-H. Suh Consultant for: Celltrion, Inc., E. Chalouhi EI Khouri Grant/research support from: Celltrion, Inc., P. Miranda Grant/research support from: Celltrion, Inc., F. F Cons Molina Grant/research support from: Celltrion, Inc., P. Shesternya Grant/research support from: Celltrion, Inc., F. MedinaRodriguez Grant/research support from: Celltrion, Inc., P. Wiland Grant/research support from: Celltrion, Inc., S. Jeka Grant/research support from: Celltrion, Inc., J. Chavez-Corrales Grant/research support from: Celltrion, Inc., T. Linde Grant/research support from: Celltrion, Inc., P. Hrycaj Grant/research support from: Celltrion, Inc., I. Hospodarskyy Grant/research support from: Celltrion, Inc., M. Abello-Banfi Grant/research support from: Celltrion, Inc., J. Jaworski Grant/research support from: Celltrion, Inc., M. Piotrowski Grant/research support from: Celltrion, Inc., W. Park Consultant for: Celltrion, Inc., S. C. Shim Consultant for: Celltrion, Inc., S. J. Lee Employee of: Celltrion, Inc., S. Y. Lee Employee of: Celltrion, Inc., D. H. Yoo Consultant for: Celltrion, Inc.

DOI: 10.1136/annrheumdis-2017-eular.6553

\section{SAT0147 SERUM LEVELS OF THE ANTI-TNF BIOLOGICS CORRELATE WITH CLINICAL EFFICACY IN PATIENTS WITH INFLAMMATORY ARTHRITIS}

C.C. Mok ${ }^{1}$, B. Fong ${ }^{1}$, L.Y. Ho ${ }^{1}$, C.H. To ${ }^{2} .{ }^{1}$ Medicine, Tuen Mun Hospital;

${ }^{2}$ Medicine, Pok Oi Hospital, HK, Hong Kong

Objectives: To study the correlation between levels of the anti-TNF biologics and clinical efficacy in patients with inflammatory arthritis

Methods: Adult patients who fulfilled the criteria for rheumatoid arthritis (RA), spondyloarthritis (SpA) and psoriatic arthritis (PSA) and were commenced on standard doses of the anti-TNF biologics were recruited. Serum samples saved at baseline, month 6 and 12 were assayed for the trough levels of the biologics ( \pm anti-drug antibodies) retrospectively. Patients were followed longitudinally and efficacy analyses were conducted at 3-month intervals without the knowledge of the drug levels. Biologics would be discontinued from 6 months onwards according to protocol-based improvement criteria for each disease. Clinical efficacy of the anti-TNF biologics was compared among patients with different levels of the drug by statistical methods.

Results: 112 patients were studied (58 RA, age $51.2 \pm 10.9$ years, disease duration $72.9 \pm 67$ months; $41 \mathrm{SpA}$, age $39.1 \pm 9.9$ years, disease duration $74.3 \pm 81.6$ months; 13 PSA, age $53.5 \pm 10.7$ years, disease duration $44.3 \pm 35.4$ years). The number of patients treated with infliximab (IFX), adalimumab (ADM), golimumab (GLM) and etanercept was $3,31,36$ and 42 , respectively. At month 12, neutralizing antibodies against IFX, ADM and GLM were present in 2 (67\%), $14(45 \%)$ and 1 $(3 \%)$ of the patients, respectively. In ADM users, the drug level was significantly lower in those with antibodies than those without $(1.81 \pm 2.63$ vs $8.02 \pm 4.14 \mathrm{ug} / \mathrm{ml}$; $\mathrm{p}<0.001$ ). Antibody titer against ADM correlated negatively with the levels of ADM (Rho $-0.72 ; p<0.001$ ). Patients were stratified arbitrarily into 3 groups for each biologic according to the trough levels of the drugs. Low drug concentrations were defined as levels $\leq 1.30 \mathrm{ug} / \mathrm{ml}, 0.05 \mathrm{ug} / \mathrm{ml}$ and $0.60 \mathrm{ug} / \mathrm{ml}$ in ADM, ETN and GLM users, respectively. In patients with RA/PSA $(\mathrm{N}=71)$, patients with the lowest anti-TNF drug level group $(\mathrm{N}=30)$ had a non-significant trend of less improvement in DAS28, CDAl scores at month 12 when compared to others $(\mathrm{N}=41)$. However, significantly more patients withdrew treatment due to inefficacy at month 12 in this group compared to others $(67 \%$ vs $7.3 \%, p<0.001)$. In patients with SpA $(\mathrm{N}=41)$, patients with lowest anti-TNF drug levels stratum $(\mathrm{N}=9)$ had significantly less improvement in ASDAS compared with others at month $12(\mathrm{~N}=32)(-0.57 \pm 0.63$ vs $-1.93 \pm 1.28 ; p=0.003)$. The proportion of patients who achieved an ASAS20 response was also significantly lower in this group of patients $(33 \%$ vs $75 \%$; $\mathrm{p}=0.04$ ). In all the 112 patients studied, the cumulative withdrawal rate of the anti-TNF biologics at month 12 (by Kaplan-Meier's analysis) was significantly higher in those with low drug levels when compared to others ( $26.1 \%$ vs $54.6 \%$; $\mathrm{p}<0.001$ by log rank test)

Conclusions: The presence of neutralizing antibodies to the anti-TNF monoclonals is associated with lower trough levels of the drugs. Trough level of the anti-TNF biologics is useful for optimizing the clinical efficacy of the drugs in patients with inflammatory arthritis.

Disclosure of Interest: None declared

DOI: 10.1136/annrheumdis-2017-eular.5681

\section{SAT0148 RABBIT RISK SCORE FOR SERIOUS INFECTIONS IN A ROMANIAN COHORT OF RHEUMATOID ATHRITIS TREATED WITH BIOLOGICS}

C. Ancuta $^{1,2}$, C. Pomirleanu ${ }^{1,2}$, R. Maxim ${ }^{2}$, L. Petrariu ${ }^{2}$, G. Strugariu ${ }^{2}$, E. Ancuta ${ }^{3}$, R. Chirieac ${ }^{4}$. ${ }^{1}$ University of Medicine and Pharmacy Grigore T Popa lasi; ${ }^{2}$ Rheumatology 2, Clinical Rehabilitation Hospital; ${ }^{3}$ Research Dept., Elena Doamna Clinical Hospital; ${ }^{4}$ Sanocare Medical \& Research Center, IASI, Romania

Background: The risk of infections, especially severe infections (SI), remains of particular interest in rheumatoid arthritis (RA), both defective immune response and therapeutic immunosuppression being responsible.

The RABBIT Risk Score (RRS), an instrument developed and validated for RA in the German Biologics Register RABBIT and replicated in other RA settings (British Register), allows the estimation of SI occurring during 12 months according to patient characteristics, based on data from similar risk profiles.

Objectives: To evaluate the RSS reliability in a Romanian RA cohort under different biologics, considering the agreement between observed and expected rates of SI at 12 months.

Methods: Longitudinal study on 272 consecutive RA with moderate-to-severe active disease, starting their biologic according to local guidelines, enrolled between 2008 and 2016 in a single academic center.

Along with disease activity and therapeutic response, baseline RRS (http://www.biologika-register.de/en/home/risk-score/) was applied for each case, based on multiple risk factors for infections including age, functional status, chronic lung and renal comorbidities, previous SI, number of treatment failures, current biologic (TNF or non-TNF inhibitors), mean corticosteroid dose.

The predictive value of RRS was considered by comparing the number and rate of expected versus reported $\mathrm{SI}$ in the first year of biologics (ROC curve, $p<0.05$ ), assessing the number of adverse events per year and per 100 patient-years, cases with at least one infection.

Statistical analysis (univariate, multivariate) was stratified according to different predictors of infection, patients being classified in two groups based on their recruitment before (2008-2012) and after (2013 up to date) implementation of national biologic register RRBR.

Results: The performance of RSS was previously established in a pilot study on 181 RA. Currently, the RSS was considered in 144 RA recruited to the first group and 128 to the second. The prescription pattern significantly changed $(p<0.05)$ for patients enrolled in last years: RA were more likely to receive earlier bDMARD, for lower activity and functional status; moreover, lower corticosteroids (dose, duration) and fewer synthetic DMARDs before starting biologics were reported $(p<0.05)$.

$24.63 \%$ RA developed SI (a total of 67 episodes, $1.47 \%$ fatal outcomes). Irrespective of RA settings and scenarios, history of biologics, specific drug administered (TNF or non-TNF), RRS indicated an outstanding agreement between the observed and expected SI rates $(p>0.05)$.

In addition, the rate of SI was lower in RA recruited after $2013(p<0.05)$, while RRS has better predictive significance in the second cohort $(p<0.05)$.

Conclusions: The RABBIT Risk Score is a consistent tool, able to predict serious infections in Romanian RA receiving biological therapy (TNF and non-TNF drugs), optimizing the selection of appropriate medication based of individual infectious risk profile in routine practice.

Disclosure of Interest: None declared

DOI: 10.1136/annrheumdis-2017-eular.2774

\section{SAT0149 COMPARATIVE EFFECTIVENESS OF TOFACITINIB, BIOLOGIC DRUGS AND TRADITIONAL DISEASE-MODIFYING ANTIRHEUMATIC DRUGS IN RHEUMATOID ARTHRITIS}

C.S. Moura ${ }^{1}$, M.A. Machado ${ }^{1}$, H. Behlouli ${ }^{1}$, J.R. Curtis ${ }^{2}$, M. Abrahamowicz ${ }^{1}$, S. Bernatsky ${ }^{1}$. ${ }^{1}$ Division of Clinical Epidemiology, McGill University, Montreal, Canada; ${ }^{2}$ Division of Clinical Immunology and Rheumatology, University of Alabama at Birmingham, Birmingham, United States

Background: Most rheumatoid arthritis (RA) patients initiate therapy with methotrexate (MTX), but only $1 / 3$ will have low disease activity with this agent alone. Several therapeutic options are available for patients with MTX-resistant RA, including new Janus kinase (JAK) inhibitors (eg.: tofacitinib).

Objectives: To compare the effectiveness of traditional disease-modifying antirheumatic drugs (DMARDs), biologic DMARDs and tofacitinib for RA patients with inadequate response to MTX.

Methods: We used MarketScan ${ }^{\circledR}$ databases (2011-2014) to study adult RA individuals previously treated with methotrexate (oral or SQ) and newly prescribed one of the medications under study. The date of first filled prescription or infusion drug was defined as the cohort entry and a 12-month pre-period was used to exclude prior users of biologics or tofacitinib. We required subjects to be continuously enrolled in the medical and pharmacy plan 12 months before and after the cohort entry. Effectiveness was access through an algorithm previously validated $^{1}$, based on the following criteria: 1) non-adherence; 2) switching/adding a new biologic or tofacitinib; 3) switching/adding a new DMARD; 4) increasing of the dose of the starting therapy; 5) use of glucocorticoid joint injections; and 6) increasing the dose of oral glucocorticoid. A patient's therapy was defined as not effective if at least one of the criterion occurred during the first year of follow-up.

Results: 16,305 RA patients were included; 2,879 began therapy with DMARD, 13,345 with biologics and 81 with tofacitinib. Among all patients, $77.5 \%$ were female and the mean age was 56.2 years (standard deviation 12.6). Table 1 shows the proportion of patients that meet the individual criterion and that achieved effectiveness at the end of one-year follow-up.

Conclusions: Similar rates of therapy effectiveness were observed among groups, although the rates for the individual criteria differed. Fewer patients initiating biologic agents were non-adherent compared to DMARD and tofacitinib therapy, but switch/adding and injections tended to be higher in this group. 